\title{
Assessment of Enzymatic Browning and Evaluation of Antibrowning Methods on Dates
}

\author{
Mariam Al-Amrani, ${ }^{1}$ Ahmed Al-Alawi $\left(\mathbb{D}^{2},{ }^{2}\right.$ and Insaaf Al-Marhobi ${ }^{2}$ \\ ${ }^{1}$ Sohar Municipality, Sohar, Oman \\ ${ }^{2}$ Department of Food Science and Nutrition, College of Agricultural and Marine Sciences, Sultan Qaboos University, Muscat, Oman \\ Correspondence should be addressed to Ahmed Al-Alawi; ahmed543@squ.edu.om
}

Received 9 October 2019; Revised 9 January 2020; Accepted 7 February 2020; Published 29 February 2020

Academic Editor: Carl J. Schaschke

Copyright (C) 2020 Mariam Al-Amrani et al. This is an open access article distributed under the Creative Commons Attribution License, which permits unrestricted use, distribution, and reproduction in any medium, provided the original work is properly cited.

\begin{abstract}
Dates' color is known to play a crucial role in determining the value and quality of the fruit. The color changes from the natural accepted golden color to unfavorable dark brown color during storage. In this study, the effect of different color preservation methods (modified atmosphere packaging, cold storage $\left(4^{\circ} \mathrm{C}\right)$, sulfur dioxide gas $\left(\mathrm{SO}_{2}\right)$, and blanching) and its relation to darkening due to action of the browning enzymes and melanin production were investigated. Polyphenol oxidase was shown to be active in all treatments except the samples treated with $\mathrm{SO}_{2}$ gas and steam blanching for ten minutes. Likewise, peroxidase activity showed a similar trend in all samples, but a decrease in activity was observed in sulfated samples and total inactivation in steam blanching for ten minutes. Moreover, sulfated samples have shown improvement in color compared to all other treatments, whereas the steamed samples showed the highest color deterioration. Concurrently, melanin content increased in all samples over the period of storage except in the sulfated samples. FTIR analyses of dates' melanin have revealed similar structural feature to the reference melanin; however, some differences were noticed in the regions $2850-2950 \mathrm{~cm}^{-1}$ and 1690 $1705 \mathrm{~cm}^{-1}$ which indicated major structural difference between the two melanin samples. More work is suggested to reveal structural and functional properties of dates' melanin.
\end{abstract}

\section{Introduction}

Date palm (Phoenix dactylifera) is considered as one of the oldest and most abundant cultivated fruit trees found in the Arabian Peninsula. The Sultanate of Oman is identified as one of largest producers of dates in the world; ranking number eight globally with an average production of 26000 MT annually [1] and palm cultivation continues to be the backbone of the vast majority of the farmers. Due to its widespread, social, nutritional, and economic importance, it has drawn enormous attention by all concerned authorities in the country. The fruit is characterized by high content of carbohydrates especially simple sugars $(70-80 \%)[2,3]$. In addition, the fruit is rich in many important nutrients such as dietary fibers $(56.5-11.5 \%)$, fat $(0.20-0.50 \%)$, proteins (2.30-5.60\%), ash (2\%), phenolic antioxidants, and vitamins [3]. In the Sultanate, $30-40 \%$ of the dates are consumed in the Rutab stage and $60-70 \%$ is consumed in the Tamar stage.
Recent statistics showed that there are eight million date palm trees in the sultanate and $78 \%$ of the total production is coming from the top five commercial date palms, which are Khalas, Zabad, Khuneizy, Khasab, and Fardh [4]. Marketability and economical value of dates in local and international markets and its related products are determined by many criteria such as color, size, and taste. The deterioration of dates during storage is a major concern and results in changes in appearance and taste [5].

Color is one of the most important attributes that affect appearance and any undesirable changes in color can manipulate consumer acceptability of the product. However, color is a very complex criterion and difficult to control since it is affected by several factors such as composition and environmental factors and can lead to undesirable changes in the fruit. One of the most serious reactions that takes place in dates during storage and affects color is browning reactions which are major chemical and physiological disorders that 
affect fruits' quality and taste in general [5-7]. These reactions can be attributed to enzymatic and nonenzymatic browning. Nonenzymatic browning reactions are further classified into two types: Maillard reaction, when reducing sugars react with proteins at moderate temperature $\left(>60^{\circ} \mathrm{C}\right)$, and caramelization when sugars react with each other at high temperature $\left(>100^{\circ} \mathrm{C}\right)$ [8]. The second major group of browning reactions is enzymatic browning which is a process that involves enzymatic action and considered as an indicator of quality loss responsible for many fresh and processed fruits and vegetables such as dates, banana, apricot, and potato. This process occurs naturally due to action of the enzyme polyphenol oxidase (PPO) in the presence of oxygen on phenolic compounds and resulting in a brown compound called $o$-Quinones. During storage, $o$-Quinones polymerize nonenzymatically to produce heterogeneous deep dark polymers called melanin [9]. Production of melanin is linked with changes in the organoleptic characteristics (e.g., it produces dark color) that lead eventually to quality deterioration and reduce its value significantly [10]. Besides PPO enzyme, the browning phenomenon in fruits and vegetables is linked also with the action of peroxidase (POD) enzyme. It has been suggested that PPO works as a promoter for POD activity because hydrogen peroxide which is a product of PPO reaction with phenolic compounds is essential for POD action [11]. POD enzymes catalyze oxidation of phenolic compounds in the presence of hydrogen peroxide to form brown compounds. Besides changing the color, action of PPO and POD enzymes has significant impact on the flavor and aroma of horticultural products, since phenolic compounds play a role in giving bitter, sweet, pungent, or astringent tastes in fruits, vegetables, and spices [11].

The extent of browning reactions varies in relation with different factors. Those are oxygen partial pressure, storage temperature, moisture content, and time. As these four factors increased, the browning also appeared to increase [8]. There are several inhibitory methods shown to control browning enzymes such as addition of certain chemical substances, heat treatment, cold storage, radiation, and other advanced techniques such as radio frequency heating. The action of PPO and POD in browning has been reported in literature for many fruits, but very little attention has been given to dates. Therefore, there are very limited reports that talk on enzymatic oxidation of polyphenols in dates during ripening and storage $[5,6,12,13]$.

Because of the importance of polyphenol oxidase in browning and the loss of quality of the dates in the tamer stage during ambient storage over a period of a few months, the aim of this study was to suggest a practical treatment or preservation method to stop or slow down the browning enzymes (PPO and POD) to preserve the surface color of dates. Treatment with sulfur dioxide has shown good results in other dried fruits; therefore, similar trend is expected to be observed with dates. It is worthwhile to mention that to the best of our knowledge, practically, no studies have been investigated on the inhibition of enzymatic browning on date fruits by sulphiting techniques.

\section{Materials and Methods}

2.1. Sample Collection. Khalas dates (soft variety) of 2016 production were used at Tamar stage for this study. The dates were received from a local farm in Bahla Wallayat, Al Dakhlia Province, which were dried traditionally under direct sun for $5 \mathrm{~h}$. Then, the samples were brought to the lab and stored in a freezer at $-20^{\circ} \mathrm{C}$ until further analysis.

2.2. Sample Preparation. The dates were first sorted manually to achieve samples of uniform golden color. The moisture content of the fruits was then checked and adjusted to $16 \%$ by drying the samples in a forced draft oven. Before any treatment, water activity $\left(a_{\mathrm{w}}\right)$, moisture content (MC), melanin content, and color were measured. The samples were then divided into five groups (control, cold storage, modified atmosphere packaging, steam blanching, and sulfation) and subjected to different controlled conditions. About $300 \mathrm{~g}$ of dates was used in each treatment (triplicate, $100 \mathrm{~g}$ for each replicate) and used for further assessment of $a_{\mathrm{w}}$, color, MC, PPO activity, POD activity, and melanin concentration at 0 , $14,30,75$, and 100 days. The control sample was placed in a polypropylene bag at room temperature $\left(25-27^{\circ} \mathrm{C}\right)$ and was used as a comparison to the treated samples to learn the effectiveness of the different treatments in the inhibition of enzymatic browning.

\subsection{Treatments}

2.3.1. Blanching. Steam blanching was the preferred method used due to its simplicity and its ability to preserve watersoluble vitamins and minerals in comparison to water blanching. Date samples were placed onto the middle shelf of the steam chamber and covered by aluminum foil to avoid steam condensation on the treated fruits. The steam was inserted at a 2 bar pressure and $98.5^{\circ} \mathrm{C}$ temperature, and the samples were blanched for three minutes and ten minutes. After the treatment, the samples were taken out of the blanching chamber, left to cool at room temperature, packed in polypropylene bags, and stored at room temperature $\left(25-27^{\circ} \mathrm{C}\right)$ until further analysis.

2.3.2. Sulfation. Date samples were placed in a forced draft oven (dimension), modified with two tubes fixed at the back. Tube one was connected to $\mathrm{SO}_{2}$ gas cylinder and was used to insert the gas, while the second tube was used to release the gas outside the oven. Both tubes were connected to a twoway valve to control the gas flow. The fruit samples were placed onto the middle shelf inside the oven; 11 of compressed $\mathrm{SO}_{2}$ gas was inserted and kept for three and half hours at $45^{\circ} \mathrm{C}$ to infuse the surface of the fruit with the gas. Moreover, oven fan was switched on to ensure equal distribution of gas over dates. After the intended time was reached, the chamber was flushed with fresh air through the first tube and the gas was let to escape through the second tube for $2 \mathrm{~h}$. The treated samples were cooled to room temperature and packed in polypropylene bags and stored at room temperature $\left(25-27^{\circ} \mathrm{C}\right)$ until further analysis. 
2.3.3. Modified Atmosphere Packaging. Nitrogen gas (9599.5\% purity) produced by a nitrogen generator was used in this experiment to modify the atmosphere over the date samples in order to eliminate oxygen. Date samples were placed in a polypropylene bag $(20 \mathrm{~cm} \times 30 \mathrm{~cm} \times 1 \mathrm{~mm})$, flushed with nitrogen gas for $10 \mathrm{~s}$ to replace air, and then the bag was sealed immediately using heat sealer. The volume ratio of gas to date sample was about $4: 1$. Finally, the samples were stored at room temperature $\left(25-27^{\circ} \mathrm{C}\right)$ until further analysis.

2.3.4. Cold Storage. Date samples were placed in polypropylene bags and stored at $4^{\circ} \mathrm{C}$ in the refrigerator. The dates were later subjected to further analysis to test the effect of cold storage on different parameters.

2.4. Chemical Analysis. The samples were used either as a whole fruit or as a paste depending on the analysis undertaken. The paste was prepared by first de-seeding the fruit then manually mixing the flesh to obtain a homogenous sample. Each analysis was done in triplicate and the mean was calculated.

2.4.1. Enzyme Crude Extract. A crude extract of the PPO and POD enzymes was obtained using the method described elsewhere [12]. In this method, four grams of date sample was homogenized in $16 \mathrm{ml}$ of $0.5 \mathrm{M}$ of potassium phosphate buffer $\left(\mathrm{K}_{3} \mathrm{PO}_{4}\right)(\mathrm{pH} 6.8)$ and $0.4 \mathrm{~g}$ of polyvinylpyrrolidone (PVP) in an ice bath for three minutes using a homogenizer (IKA T-18 Ultra Turrax Digital Homogenizer, Germany). After one minute of homogenization, the sample was let to rest for $20 \mathrm{~s}$ to avoid overheating. The homogenate was then centrifuged at $14,000 \mathrm{rpm}$ for $20 \mathrm{~min}$ at $4^{\circ} \mathrm{C}$. The supernatant was collected and filtered through $0.2 \mu \mathrm{m}$ nylon syringe filters (Whatman, UK). The filtered supernatant was used immediately for PPO and POD activity assessment.

2.4.2. PPO Activity Assessment. The method described by Jiang [13] was used in this study with minor modifications. The enzyme crude extract was incubated in water bath for $5 \mathrm{~min}$ at $30^{\circ} \mathrm{C}$ before the reaction to optimize and standardize enzyme activity. This step was found to be critical to get consistent results. After the incubation, $0.5 \mathrm{ml}$ of the 4-methylcatechol (substrate) solution was added to $2.4 \mathrm{ml}$ of $0.5 \mathrm{M}$ potassium phosphate buffer ( $\mathrm{pH} 7.0$ ). Then, $0.1 \mathrm{ml}$ of the crude enzyme extract was added. The mixture was mixed well by inversion for few seconds and then was immediately inserted in the sample holder compartment of the UV-Visible spectrophotometer (Shimadzu UV-1650PC, Japan) which was temperature controlled at $30^{\circ} \mathrm{C}$. Immediately, the measurement was taken at $420 \mathrm{~nm}$ for $5 \mathrm{~min}$. Enzyme activity was calculated from the steady line at the early stage of the reaction. One unit of enzyme activity was defined as the amount that caused a change of 0.01 in the absorbance per minute.

2.4.3. POD Activity Assessment. POD activity was assayed using the method described by Lin et al. [14] with minor modification. The enzyme extract was incubated in water bath for $5 \mathrm{~min}$ at $30^{\circ} \mathrm{C}$ before the reaction. $0.025 \mathrm{ml}$ of the enzyme extract was added to $2.78 \mathrm{ml}$ of $0.5 \mathrm{M}$ potassium phosphate buffer ( $\mathrm{pH} 7.0)$ and $0.1 \mathrm{ml}$ of $1 \%$ hydrogen perox- ide. Then, $0.1 \mathrm{ml}$ of $4 \%$ guaiacol substrate was added to the mixture. The mixture was mixed well by inversion for few seconds and then the sample was immediately inserted in the sample holder compartment of the UV-Visible spectrophotometer (Shimadzu UV-1650PC, Japan) which was temperature controlled at $30^{\circ} \mathrm{C}$. Immediately, the absorption at $470 \mathrm{~nm}$ was recorded for $5 \mathrm{~min}$. Enzyme activity was calculated from the steady line at the early stage of the reaction. One unit of enzyme activity was defined as the amount that caused a change of 0.01 in absorbance per minute.

2.4.4. Color Assessment. The color readings were determined using Minolta colorimeter (Japan) following instructions of the manufacturer, where $L$ value represents lightness, $a$ value for redness/greenness, and $b$ value for yellowness/blueness. About 30 to 40 date pieces were placed in a weighing boat, and color readings were taken from different angles. After every three readings per sample, date samples were mixed, and color readings were retaken. Twelve readings were taken for each sample and then the mean was calculated. The hue angle [15] was used in this study to process the color readings to compare the differences in color between treatments; the following formula was used for this purpose:

$$
\text { Hue index }=\tan -1\left(\frac{b}{a}\right) \text {. }
$$

2.4.5. Melanin Content Assessment. The method described by Kannan and Ganjewala [16] was followed in this section with minor modifications. About $50 \mathrm{~g}$ of deseeded dates was mixed with $375 \mathrm{ml}$ of $0.5 \mathrm{M}$ sodium hydroxide ( $\mathrm{pH} 10.5$ ) and homogenized by a blender (IKA-Werke, Germany). The homogenates were incubated for 24 hours at room temperature with continuous stirring. The $\mathrm{pH}$ value of the mixture was checked frequently (every $8 \mathrm{~h}$ ) during the incubation period to monitor and adjust any change in $\mathrm{pH}$ value. Then, the sample was centrifuged at $8000 \mathrm{rpm}$ for $15 \mathrm{~min}$. The precipitate was discarded and the supernatant was collected and acidified with $1 \mathrm{M}$ hydrochloric acid to reach $\mathrm{pH} 2.5$, incubated at room temperature for two hours, and then centrifuged at $4000 \mathrm{rpm}$ for $15 \mathrm{~min}$. The precipitate was collected and the supernatant was discarded. The precipitate was then purified by acid hydrolysis using $6 \mathrm{M}$ hydrochloric acid at $100^{\circ} \mathrm{C}$ for $2 \mathrm{~h}$ to remove carbohydrates and proteins. The mixtures were then centrifuged at $8000 \mathrm{rpm}$ for $15 \mathrm{~min}$. The precipitate was redissolved in $20 \mathrm{ml}$ of $0.5 \mathrm{M}$ sodium hydroxide $(\mathrm{pH} 10.5)$ and again centrifuged at $8000 \mathrm{rpm}$ for $15 \mathrm{~min}$. The supernatant obtained was acidified again by adding $10 \mathrm{ml}$ of $1 \mathrm{M}$ hydrochloric acid to reach $\mathrm{pH} 2.5$ and again centrifuged at $8000 \mathrm{rpm}$ for $15 \mathrm{~min}$. The supernatant was discarded and the precipitate containing melanin was washed with $30-40 \mathrm{ml}$ distilled water and again centrifuged at $8000 \mathrm{rpm}$ for $15 \mathrm{~min}$. The partially purified melanin sample was finally freeze dried for $72 \mathrm{~h}$, weighted, and placed in a plastic bottle for storage in a refrigerator at $4^{\circ} \mathrm{C}$ until further analysis.

2.4.6. FTIR (Fourier-Transform Infrared) Analysis. The extracted partially purified melanin powder from the various 
treatments was analyzed following the method described by Al-Alawi et al. [17] using Cary 620 spectrometer (Agilent, USA) equipped with diamond ATR cell. For comparison, a synthetic reference melanin sample obtained from Sigma was used in this study. The IR spectrum of the experimental sample was gathered by averaging 32 scans at 4 as value of resolutions.

2.5. Statistical Analysis. All tests were carried out in triplicate and reported as the mean \pm standard deviation (SD). The significant differences between means were analyzed using Duncan's multiple range test $(P<0.05)$ using Microsoft Excel program (2016) with XLSTAT 2019.3.1 add on (Addinsoft Inc., NY, USA).

\section{Results and Discussion}

3.1. Polyphenol Oxidase Activity. The effect of different preservation methods on polyphenol oxidase is shown in Figure 1 . During 100 days of storage at $25-27^{\circ} \mathrm{C}$, all treatments except those exposed to sulfite or ten minutes steaming showed steady and gradual increase in the polyphenol oxidase activity. For all treatments except sulfation and ten minutes steaming, the difference between means for the groups showed no significant differences in the activity of PPO enzymes in the first 30 days of storage; however, the change is significant afterwards. In addition, differences between treatments showed no significant differences between treatments at the same period. A similar trend was also reported on minimal processed Barhi dates stored over a period of 9 months in frozen storage [15]. The results also demonstrate successful and complete inactivation of the enzyme by sulfation and ten minutes steam blanching treatments where PPO showed zero activity. The enzyme inactivation is attributed to reaction of $\mathrm{SO}_{2}$ with thiol groups and disulfide bonds that stabilizes enzyme structure [18]. Effectiveness of the treatment depends on several parameters such as product, ripening stage, treatment duration, and concentration used [19]. On the contrary, the effect induced by sulfur dioxide was reported in other literatures to weaken because oxygen in the ambient air reoxidizes the bleached compounds, restoring the original color and enzymes regain their activity [20]. However, the results presented in our study showed no reactivation of PPO enzyme during 100 days of storage at room temperature. Similar results were also reported with blueberry when treated with sodium metabisulfite or blanching at $85^{\circ} \mathrm{C}$ for $20 \mathrm{~min}$ [21] and dried apricot when treated with sulfur dioxide gas [19].

Cold storage at $4^{\circ} \mathrm{C}$ showed no detrimental effect on PPO, and the enzyme activity was maintained; thus, high activity of PPO was reported during storage. At the end of storage period (100 days), the activity was found to be $27.2 \mathrm{U} / \mathrm{min}$ which was similar to the activity of the control sample (29.6 U/min). This result was expected and can be explained through an established practice that low temperature is generally used to preserve biological materials by slowing down rate of reactions, but without causing any damage to the reactants. Similar results were also reported in refrigeration storage of blueberry and strawberry [21, 22].

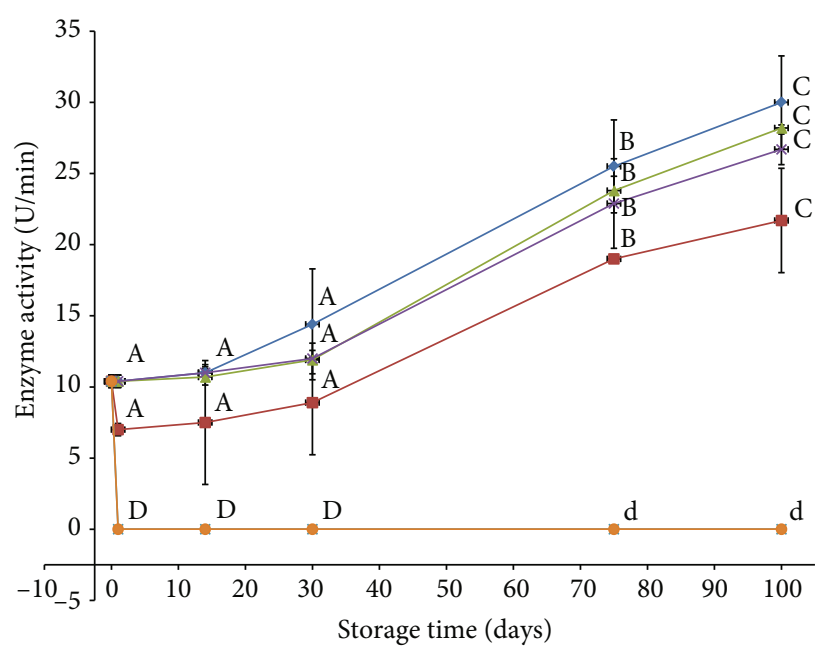

FIGURE 1: Effect of different preservation methods on polyphenol oxidase activity during storage. Control $(\downarrow), \mathrm{SO}_{2}(\bullet)$, cold storage $(\boldsymbol{A})$, blanching three minutes ( $\boldsymbol{\square})$, modified atmosphere packaging $(X)$, and blanching ten minutes $(*)$. Same letter indicates no statistical differences between groups.

Blanching is one of the techniques which have been extensively used for treating agricultural produce with steam or hot water for short period $1-10 \mathrm{~min}$ at $75-95^{\circ} \mathrm{C}$. Time and temperature combination is an important factor in this technique and mainly depends on the type of fruit and vegetable [23]. Severe blanching can have negative effect on nutrients which are relatively unstable when subjected to heat treatments, such as vitamins and phenolic compounds [24]. The results shown in Figure 1 demonstrated partial inactivation of PPO enzyme in samples steamed for three minutes (decrease in activity, although it is not significant) and complete inactivation at ten minutes. In comparison with the other active treated samples, it is worth to mention that enzyme activity for samples steamed for three minutes showed the lowest activity $(21.7 \mathrm{U} / \mathrm{min})$ at the end of storage period. This indicates that PPO has high thermal stability and the treatment time (three minutes) was not sufficient to cause pronounced inactivation in its activity as statistical analysis for differences between treatments showed no significant differences between treatments. Work done on Deglet Nour date showed that blanching at $55^{\circ} \mathrm{C}$ for $20 \mathrm{~min}$ was not enough to inhibit PPO [7]. On the other hand, another work on Deglet Nour and Ghars dates [11] showed that heating for one hour at $80^{\circ} \mathrm{C}$ is enough to completely inhibit PPO activity. Other reports showed two minutes at $85^{\circ} \mathrm{C}$ are not enough to inactivate PPO in blueberry [21].

PPO activity for modified atmosphere packaging on the other hand was found to be lower (about $26.0 \mathrm{U} / \mathrm{min}$ ) compared with the control $(29.6 \mathrm{U} / \mathrm{min})$ and refrigerated (27.2 U/min) samples. Although, many reports have showed that nitrogen treatment of fruits and vegetables significantly inhibits polyphenol oxidase activity [25], our results showed ineffectiveness of this treatment towards PPO in dates. This could be attributed to the high permeability of polypropylene films to oxygen especially at temperatures $25-27^{\circ} \mathrm{C}$ 
[26]. Furthermore, some gases formula such as " $85 \% \mathrm{CO}_{2}+$ $3 \% \mathrm{O}_{2}$ " was shown to have slight decrease on polyphenol oxidase activity in Sayer date which helped in decreasing discoloration [27].

3.2. Peroxidase Activity. Peroxidase enzyme as it was described earlier contributes besides PPO to the browning reactions through reduction of diphenols [28]. Figure 2 shows the changes in POD enzyme activity over 100 days of storage. The results showed complete inactivation of POD enzymes by steam blanching for $10 \mathrm{~min}$ whereas the enzymes were active in all the other treatments. Differences between means for the groups showed no significant differences in the activity of POD enzymes in the first 30 days of storage in all treatments (other than 10 min blanching); however, the change was significant afterwards in the control sample as well as MAP treatment, at 75 days in cold storage and three minutes' steam blanching treatments and at 100 days in the sulfation treatment. In addition, differences between treatments showed no significant differences between treatments in the first 30 days; however, the differences were evident afterwards. In $\geq 75$ days of storage, treatments can be grouped into three groups significantly distinct from each other. The first group is control and MAP treatments, the second group is three minutes steaming and cold storage treatments, and the last group is sulfation treatment. An earlier work on bamboo shoots [29] showed that MAP did not inhibit POD activity in bamboo shoots. Similar work on "níscalos" [30] concluded that activity of the POD enzyme is not affected by MAP. These results are attributed to the fact that this treatment does not cause any damage (partial nor complete) to the enzyme; therefore, the enzyme remained intact and active.

Cold storage is another preservation method where all reactions take place, but at a lower rate. The results obtained in this study showed that POD activity had a steady increase in dates stored at $4^{\circ} \mathrm{C}$ for three months. In comparison with the control sample, enzyme activity of chilled sample was found significantly low (about $19.8 \mathrm{U} / \mathrm{min}$ ) at the end of storage period (27.9 $\mathrm{U} / \mathrm{min}$ in the control sample), but still higher than the initial activity. Similar finding in dates was reported by Khali and Selselet-Attou [7] where POD activity was found to be enhanced during cold storage $\left(10^{\circ} \mathrm{C}\right)$. However, other researchers found contrary results to our findings. For example, Chisari et al. [22] reported significant inactivation of POD (between $47 \%$ and $34 \%$ ) in two types of strawberry during cold storage.

In the blanched samples, the activity of POD was zero in $10 \mathrm{~min}$ treatment throughout storage period and generally lower in three min treatment compared to the control, MAP, and cold storage. The activity found to be "16.6 U/min" in the third month. However, its activity increased gradually during storage period, a similar trend for all treatments. Previous works on dates' POD showed that blanching at $55^{\circ} \mathrm{C} / 20 \mathrm{~min}$ has no noticeable effect on its activity [7], but treatment at $100^{\circ} \mathrm{C} / 14 \mathrm{~min}$ did result in complete inactivation [6]. Our results, however, claim shorter treatment time $(10 \mathrm{~min})$ is sufficient to achieve complete and permanent inactivation of POD enzymes in dates. Our

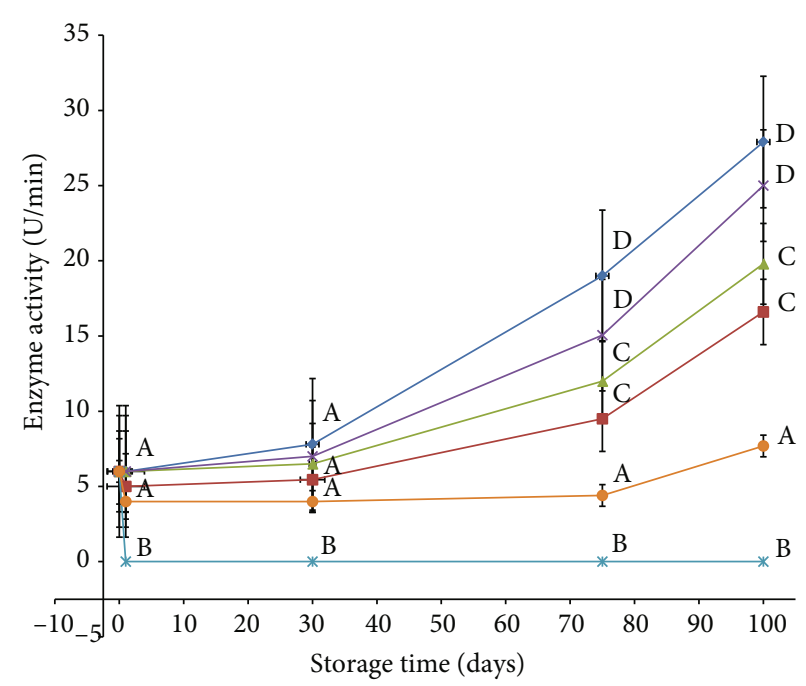

Figure 2: Effect of different preservation methods on peroxidase activity during storage. Control $(\boldsymbol{\downarrow}), \mathrm{SO}_{2}(\boldsymbol{\bullet})$, cold storage $(\boldsymbol{A})$, blanching three minutes $(\boldsymbol{\square})$, modified atmosphere packaging $(X)$, and blanching ten minutes $(*)$. Same letter indicates no statistical differences between groups.

results also suggest that an even shorter time could be sufficient to inactivate the enzyme; however, no further trails were conducted to validate this suggestion.

It is evident from Figure 2 that the activity of POD in sulfated samples was greatly reduced in comparison with the control and other treatments $(P<0.05)$. Moreover, its activity did not significantly change during the storage period (less than 100 days) $(P<0.05)$. This suggests that modification in enzyme structure took place at the time of treatment. Similar results were reported with foliage [31] and cauliflower treated with $\mathrm{SO}_{2}$ [32]. In addition, incomplete inactivation of POD enzyme could be attributed to presence of POD isoenzymes with limited presence of thiol/disulfide bonds in POD enzymes; therefore, nominal effect was seen by the treatment. It also seems that POD from different sources has the same property. This suggestion is further supported by a recent work [33] that showed different POD isoenzymes in three types of vegetables maize, tomato, and beans fumigated with $\mathrm{SO}_{2}$ gave same results. Furthermore, Figure 2 also shows slight increase in the activity of the POD enzyme on 100 days of storage. Sen et al. [20] reported similar observation after nine months of treatment in apricot and the color became darker as the storage period prolonged. Increase in enzyme activity is attributed to regaining enzymes to their activity. Regaining activity is a result of losing $\mathrm{SO}_{2}$ from the matrix due to oxidation to sulfate; in addition, $\mathrm{SO}_{2}$ molecules engaged in the inhibition reactions may participate in other side reaction to form other sulfurcontaining compounds as storage prorogates [34].

3.3. Hue Index. Color is an important criterion that reflects quality and manipulates consumer acceptance towards agricultural products and many other products. Figure 3 illustrates the hue index that characterizes the bright yellow and red color of date fruit during storage conditions. Higher 


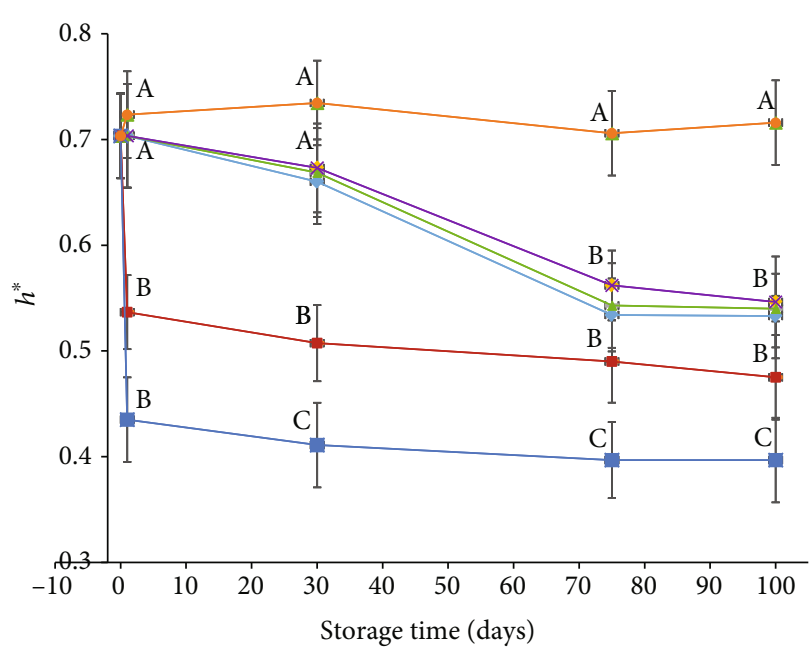

Figure 3: Hue index for different preservation methods during 100 days of storage at room temperature $(P$ value $<0.05)$. Control $(\$)$, $\mathrm{SO}_{2}(\bullet)$, cold storage $(\boldsymbol{\Lambda})$, blanching three minutes $(\boldsymbol{\square})$, modified atmosphere packaging $(X)$, blanching ten minutes $(*)$. Same letter indicates no statistical differences between groups.

is the value, lighter is the color, and vice versa. The hue index for the control sample decreased considerably during storage period from $0.7016 \pm 0.049$ at day one to $0.5333 \pm 0.05$ at the end of the experiment. Difference between means for the groups showed no significant differences in color in the first 30 days of storage in control, MAP, and cold treatments; however, the change was significant afterwards. In case of $\mathrm{SO}_{2}$ treatments, statistical analysis showed no significant changes in color during 100 days of storage. Furthermore, differences between treatments showed no significant differences between treatments $\mathrm{SO}_{2}$, MAP, cold storage, and control in the first 30 days of storage and then the deterioration in color was shown to be significant in MAP, control, and cold storage in comparison with $\mathrm{SO}_{2}$ treatments.

The hue index for the three minutes blanched samples had drastic deterioration immediately after the treatment and slow gradual changes during storage; however, differences between groups analysis showed that the change is not significant during storage. Differences between treatments analysis showed the differences in color are significant between three minutes blanching treatment in one hand and control, MAP, and cold storage treatments from the other hand in the first 30 days and the difference is not significant after 75 days of storage. Although this treatment showed reduction on activity of browning enzymes (Figures 1 and 2 ), presence of high amount of sugar in dates along with high temperature $\left(\sim 98^{\circ} \mathrm{C}\right)$ caused more browning due to nonenzymatic browning reactions (caramelization and Maillard reactions). Steaming for ten minutes, on the other hand, caused even more detrimental color change on the treated fruits which was very evident from the hue value readings; hence, the fruits appeared very dark. Although this treatment was efficient to inactivate browning enzymes, nonenzymatic browning reactions took place at a higher rate due to the prolonged heating period (ten minutes). Due to dramatic color lose at ten minutes steaming treatment, we decided to not go further with this treatment. Similar findings were reported with Stamaran date fruits [3] where yellow color was significantly darkened due to nonenzymatic reactions.

MAP results indicated a notable change in hue index values which decreased with time from $0.702 \pm 0.049$ at day one to $0.543 \pm 0.043$ after 100 days. However, the results showed higher scores compared to control sample, but the difference was not significant. This result indicates a sign of halting browning reactions that involve PPO enzymes since oxygen (as a reactant) was absent in this treatment. These results were similar to those observed in apples [35] where the degree of yellowness and lightness was not affected during MAP treatments.

Cold storage treatment proved satisfactory in preserving the golden color compared to all other treatments except sulfate method. The index decreased slowly to reach 0.573 \pm 0.012 at the end of storage period which was higher than the control sample. Work on Deglet Nour dates [36] showed that cold storage decreased color variation during storage at $5^{\circ} \mathrm{C}$. Moreover, studies on Sukkary and Khalas stored at $5^{\circ} \mathrm{C}$ also maintained its color during storage period [37]. The reason for such results was attributed to the effect of low temperatures in slowing down the enzymatic reactions.

The hue index of dates treated with sulfur dioxide gas increased immediately after the treatment (from $0.703 \pm$ 0.051 to $0.724 \pm 0.056$ ) and remained relatively constant during storage. Besides the efficacy of sulfution treatment in inactivation of PPO (complete inactivation, Figure 1) and POD (partial inactivation, Figure 2), the increase in brightness of the yellow color is mainly attributed to conversion of the intermediate $o$-Quinones to a colorless compounds called sulfoquionons $[38,39]$ and removal of carbonyl chromophores in melanoid structures that led to bleaching effect on the dark pigment [40]. Furthermore, sulfur dioxide is known to be very strong reducing agent; therefore, it also removed hydrogen peroxide which is an important factor in the second browning enzyme peroxidase. Similarly, slightest browning and a more profound yellow color was observed in dried apricot treated with $\mathrm{SO}_{2}$ [19]. These results are in good agreement to the work done on dried apricot treated with sulfur dioxide where the color did not darken during storage [41].

3.4. Melanin. The increase in the concentration of the dark or brown pigment (melanin) which is the end product of the enzymatic browning reactions was investigated for 100 days in response to the different treatments. Figure 4 demonstrates the differences in melanin concentration between the different treatments during storage period.

It was clearly noticeable from Figure 4 that there were significant differences between the different treatments $(P<0.05)$ over 100 days of storage. The control sample had the highest concentration in melanin (about $0.0859 \pm 0.004$ $\%)$ at the end of the storage period. It is evident that the increase was due to the active browning enzymes (polyphenol oxidase and peroxidase enzymes) as explained in Sections 3.1 and 3.2. As the browning enzymes remained active, the melanin quantity continued to rise. 


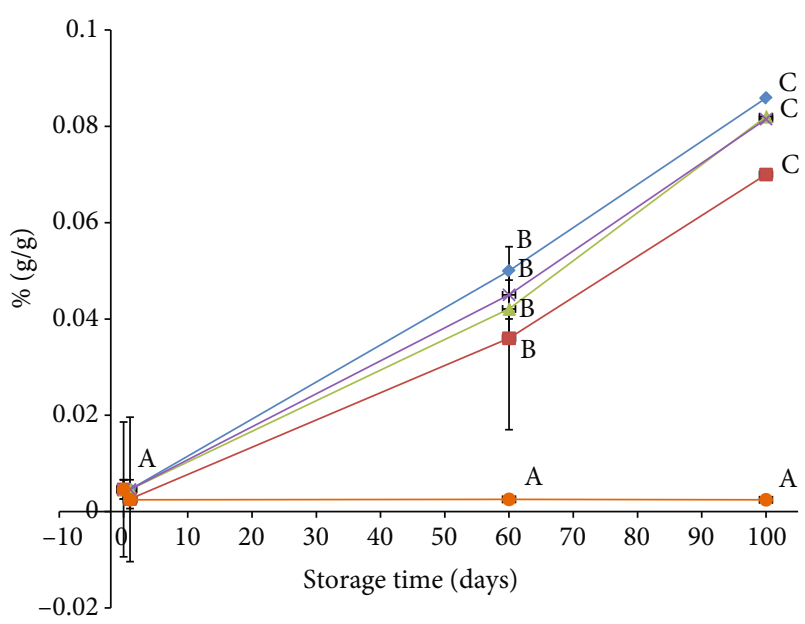

Figure 4: Melanin concentration (\%) obtained by the different preservation methods during storage $(P$ value $<0.05)$. Control $(\downarrow), \mathrm{SO}_{2}(\bullet)$, cold storage $(\boldsymbol{\Delta})$, blanching three minutes $(\boldsymbol{\square})$, and modified atmosphere packaging $(X)$. Same letter indicates no statistical differences between groups.

MAP and cold storage had the same trend as the control sample with an increased trend over time. However, MAP had lower percentage of melanin $(0.0815 \pm 0.005 \%)$ compared to that in cold storage $(0.0821 \pm 0.006 \%)$ at the end of storage period. This observation can be explained by the fact that peroxidase enzyme can work in the absence of oxygen. Moreover, this enzyme was found highly active in MAP than in cold storage as it has been discussed earlier in Section 3.2. Furthermore, as explained in Section 3.1, sthe PPO activity was found partially low compared to cold storage preservation, thus causing an increase in formation of melanin.

On the other hand, sulfated samples showed inhibition of melanin formation. It was found that there was no significant difference in melanin quantity throughout the storage period. These findings successfully support the results presented in Section 3.4 which showed improvements in the color of the treated date fruits with time. However, the slight increase in melanin concentration $(0.0244 \pm 0.00001 \%)$ can be related to the activity of peroxidase enzyme. Comparable results were reported in white Pacific shrimp, and the results were attributed to the enzymatically produced $o$-Quinone's and stopping their condensation to melanin through formation of intermediate Quinone called sulfoquinone [39, 40].

3.5. FTIR Analysis of Melanin. Figure 5 illustrates IR spectrum of dates' melanin and reference melanin (synthetic melanin, obtained from Sigma). All treatments gave melanin with same IR spectrum; therefore, only one spectrum is shown in Figure 5.

The spectral patterns for both melanin pigments are having same characteristic peaks corresponding to equivalent functional groups in melanin, though there are some differences observed. For example, both spectra showed broad and strong absorption at $3375 \mathrm{~cm}^{-1}, 3240 \mathrm{~cm}^{-1}$, and $1615 \mathrm{~cm}^{-1}$ which indicate the presence of phenol O-H groups (stretching), secondary $\mathrm{N}-\mathrm{H}$ groups (stretching), and

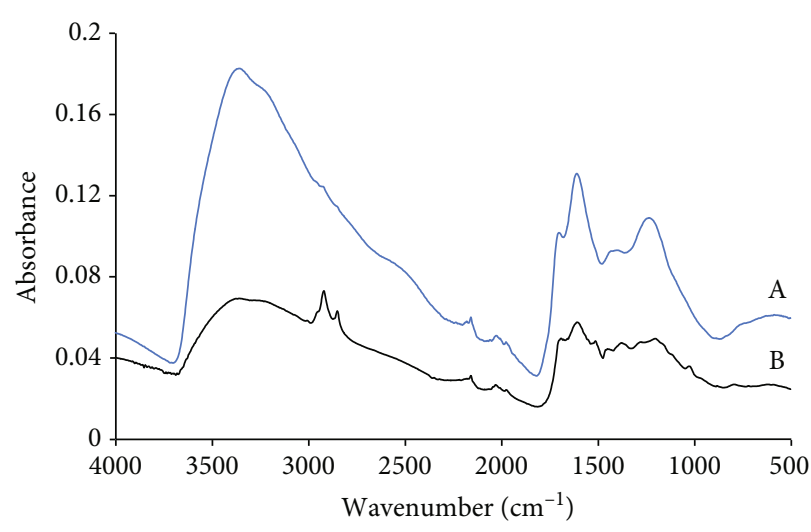

FIGURE 5: FTIR spectra of partially purified dates' melanin (B) and reference melanin $(\mathrm{A})$.

aromatic ring $\mathrm{C}=\mathrm{C}$ group $/ \mathrm{N}-\mathrm{H}$ bond, respectively. Strong and characteristic band was observed at $1705 \mathrm{~cm}^{-1}$ in the reference melanin, whereas dates' melanin showed maximum peak absorption at $1690 \mathrm{~cm}^{-1}$ and a shoulder at $1705 \mathrm{~cm}^{-1}$. The absorption at $1705 \mathrm{~cm}^{-1}$ is attributed to $\mathrm{C}=\mathrm{O}$ stretching vibration of carboxylic/aromatic aldehyde groups, whereas the peak at $1690 \mathrm{~cm}^{-1}$ is indicative of $\mathrm{C}=\mathrm{O}$ stretching vibration of conjugated ketone groups. In addition, dates' melanin showed strong absorption at $2850 \mathrm{~cm}^{-1}$, $2920 \mathrm{~cm}^{-1}$, and $2950 \mathrm{~cm}^{-1}$ (shoulder) which are attributed to asymmetric stretch vibration of aliphatic $\mathrm{C}-\mathrm{H}_{3}$ groups, asymmetric stretch vibration of aliphatic $\mathrm{C}-\mathrm{H}_{2}$ groups, and symmetrical stretch vibration of aliphatic $\mathrm{C}-\mathrm{H}_{3}$ groups, respectively. Furthermore, the dates' melanin showed absorption at $3007 \mathrm{~cm}^{-1}$ which is an indication of C-H stretching symmetric vibration of the cis double bonds. In both samples, there was no indication for the presence of $\mathrm{C}=\mathrm{O}$ amide carbonyl group (no bands in the region $1630-1690 \mathrm{~cm}^{-1}$ ). The core differences between the two samples were seen in the region $2850-2950 \mathrm{~cm}^{-1}$ and $1690-1705 \mathrm{~cm}^{-1}$; hence, the former represents possible contamination with other dates' compounds such as carbohydrates, proteins, and oils, and the latter demonstrates fundamental structural differences.

\section{Conclusion}

This study demonstrated that there was good positive correlation between the presences of PPO and POD and increase in melanin concentration. Sulfur dioxide treatment showed successful inhibition of the PPO, and regaining activity was not noticed during the full period of storage (100 days) at room temperature. Moreover, the melanin quantity remained largely unchanged during the storage period which confirms the finding of PPO inhibition results. The small increase in melanin concentration was assumed to be a result of POD activity which showed significant activity in sulfated sample; this could be because peroxidase enzymes have little thiol/disulfide bonds or insufficient amount of the sulfur dioxide used and/or time of exposure was not enough.

Mild thermal treatment $\left(98.5^{\circ} \mathrm{C} / 3 \mathrm{~min}\right)$ was proven not effective in inactivating PPO and POD enzymes, whereas sever thermal treatments $\left(98.5^{\circ} \mathrm{C} / 10 \mathrm{~min}\right)$ showed total 
inactivation of browning enzymes. However, sever thermal treatment accelerated nonenzymatic browning reactions which led to faster rate of discoloration; therefore, it is not recommended as an option to preserve dates' color.

Other treatments such as modified atmosphere packaging and cold storage had a slightly less effect on the activity of PPO compared to the control which resulted in the loss of its golden color as compared to the sulfated samples. Moreover, melanin percentage found to be high in both treatments and gave reading in the range $0.0815 \%$ and $0.08206 \%$, respectively. Those values are close to the control sample $(0.0859 \%)$.

IR analyses of dates' melanin have revealed similar structural feature to the reference melanin; however, some differences were noticed. The IR spectral difference in the region $2850-2950 \mathrm{~cm}^{-1}$ indicates possible contamination with other aliphatic compounds present in dates, whereas differences in the region $1690-1705 \mathrm{~cm}^{-1}$ could indicate major structural difference between the two melanin samples. More work is suggested to reveal structural and functional properties of dates' melanin.

From this study, it could be concluded that sulfur dioxide treatment was considerably effective in deactivating PPO in Khalas date at Tamar stage as well as obtaining a high hue index score (yellow color) indicating color preservation which is crucial in determining the quality of the date fruit and its market value.

\section{Data Availability}

All the data used to support the findings of this study are from previously reported studies and datasets, which have been cited in this manuscript. Furthermore, the processed data will be provided upon request.

\section{Conflicts of Interest}

The authors declare that they have no conflicts of interest.

\section{Acknowledgments}

Mariam Al-Amrani would like to thank Sohar Municipality for providing scholarship for her MSc studies. In addition, financial support provided by the Sultan Qaboos University under the Internal Grant IG/AGR/FOOD/16/02 and IG/AGR/FOOD/19/01 is greatly appreciated and acknowledged. The valuable statistical assistance provided by Dr. Michel Claerboudt is highly appreciated.

\section{References}

[1] R. Al-Yahyai and M. M. Khan, "Date palm status and perspective in Oman," in Date Palm Genetic Resources and Utilization, J. M. al-Khayri, S. M. Jain, and D. V. Johnson, Eds., pp. 207240, Springer, Dordrecht, 2015.

[2] S. Ghnimi, S. Umer, A. Karim, and A. Kamal-Eldin, "Date fruit (Phoenix dactylifera L.): An underutilized food seeking industrial valorization," NFS Journal, vol. 6, pp. 1-10, 2017.

[3] I. Hazbavi, M. H. Khoshtaghaza, A. Mostaan, and A. Banakar, "Effect of postharvest hot-water and heat treatment on quality of date palm (cv. Stamaran)," Journal of the Saudi Society of Agricultural Sciences, vol. 14, no. 2, pp. 153-159, 2015.

[4] R. Al-Yahyai and S. Al-Khanjari, "Biodiversity of date palm in the Sultanate of Oman," African Journal of Agricultural Research, vol. 3, no. 6, pp. 389-395, 2008.

[5] R. Ahlam, M. Cheb, K. Mohammed, and Y. Mami, "Impact of heat treatment on polyphenol oxidase and peroxidase action in Algerian stored dates," International Journal of Agricultural Sciences, vol. 5, no. 3, pp. 517-520, 2015.

[6] I. Rashid, Oxidizing enzymes in dates in relation to the darkening of fruit, [Ph.D. thesis], Mass. University, Amherst, 1959, Taken from R. Ahlam, M. Cheb, K. Mohammed, Y. Mami, "Impact of heat treatment on polyphenol oxidase and peroxidase action in Algerian stored dates," International Journal of Agricultural Sciences, vol 5, no 3, pp. 517-520, 2015.

[7] M. Khali and G. Selselet-Attou, "Effect of heat treatment on polyphenol oxidase and peroxidase activities in Algerian stored dates," African Journal of Biotechnology, vol. 6, no. 6, pp. 790-794, 2007.

[8] A. A. Kader and A. M. Hussein, Harvesting and postharvest handling of dates, ICARDA, Aleppo, 2009.

[9] H.-j. Li, J.-x. Li, and Z. Zhao, "Characterization of melanin extracted from apricot (Armeniaca sibirica) and its effect on hydrazine-induced rat hepatic injury," ScienceAsia, vol. 42, no. 6, pp. 382-391, 2016.

[10] J. J. Nicolas, F. C. Richard-Forget, P. M. Goupy, M.-- J. Amiot, and S. Y. Aubert, "Enzymatic browning reactions in apple and apple products," Critical Reviews in Food Science and Nutrition, vol. 34, no. 2, pp. 109-157, 1994.

[11] F. A. Tomás-Barberán and J. C. Espin, "Phenolic compounds and related enzymes as determinants of quality in fruits and vegetables," Journal of the Science of Food and Agriculture, vol. 81, no. 9, pp. 853-876, 2001.

[12] S. D. Amiour and L. Hambaba, "Effect of $\mathrm{pH}$, temperature and some chemicals on polyphenoloxidase and peroxidase activities in harvested Deglet Nour and Ghars dates," Postharvest Biology and Technology, vol. 111, pp. 77-82, 2016.

[13] Y. Jiang, "Role of anthocyanins, polyphenol oxidase and phenols in lychee pericarp browning," Journal of the Science of Food and Agriculture, vol. 80, no. 3, pp. 305-310, 2000.

[14] Z. F. Lin, S. S. Li, D. L. Zhang et al., "The changes of pigments, phenolic content and activities of polyphenol oxidase and phenylalanine ammonia-lyase in pericarp of postharvest litchi fruit," Acta Botanica Sinica, vol. 30, pp. 40-45, 1988.

[15] A. Alhamdan, B. Hassan, H. Alkahtani, M. Younis, and D. Abdelkarim, "Quality changes in fresh date fruits (Barhi) during individual quick freezing and conventional slow freezing," Pakistan Journal of Agricultural Sciences, vol. 53, no. 4, pp. 917-924, 2016.

[16] P. Kannan and D. Ganjewala, "Preliminary characterization of melanin isolated from fruits and seeds of Nyctanthes arbortristis," Journal of Scientific Research, vol. 1, no. 3, pp. 655661, 2009.

[17] A. A. Al-Alawi, I. M. Al-Marhubi, M. S. M. Al-Belushi, and B. Soussi, "Characterization of carrageenan extracted from Hypnea bryoides in Oman," Marine Biotechnology, vol. 13, no. 5, pp. 893-899, 2011.

[18] L. Schroeter, Sulfur Dioxide, Applications in Foods, Beverages and. Pharmaceuticals, Pergamon Press, Oxford, 1966.

[19] A. L. Coşkun, M. Türkyılmaz, Ö. T. Aksu, B. E. Koç, O. Yemiş, and M. Özkan, "Effects of various sulphuring methods and 
storage temperatures on the physical and chemical quality of dried apricots," Food Chemistry, vol. 141, no. 4, pp. 36703680, 2013.

[20] F. Sen, M. Ozgen, B. M. Asma, and U. Aksoy, "Quality and nutritional property changes in stored dried apricots fumigated by sulfur dioxide," Horticulture, Environment, and Biotechnology, vol. 56, no. 2, pp. 200-206, 2015.

[21] M. Siddiq and K. D. Dolan, "Characterization of polyphenol oxidase from blueberry (Vaccinium corymbosum L.)," Food Chemistry, vol. 218, pp. 216-220, 2017.

[22] M. Chisari, R. N. Barbagallo, and G. Spagna, "Characterization of polyphenol oxidase and peroxidase and influence on browning of cold stored strawberry fruit," Journal of Agricultural and Food Chemistry, vol. 55, no. 9, pp. 3469-3476, 2007.

[23] A. Patras, N. P. Brunton, B. K. Tiwari, and F. Butler, "Stability and degradation kinetics of bioactive compounds and colour in strawberry jam during storage," Food and Bioprocess Technology, vol. 4, no. 7, pp. 1245-1252, 2011.

[24] D. F. Olivera, S. Z. Vina, C. M. Marani et al., "Effect of blanching on the quality of Brussels sprouts (Brassica oleracea L. gemmifera DC) after frozen storage," Journal of Food Engineering, vol. 84, no. 1, pp. 148-155, 2008.

[25] D. Zhang, P. C. Quantick, J. M. Grigor, R. Wiktorowicz, and J. Irven, "A comparative study of effects of nitrogen and argon on tyrosinase and malic dehydrogenase activities," Food Chemistry, vol. 72, no. 1, pp. 45-49, 2001.

[26] M. Pannirselvam, A. Genovese, M. C. Jollands, S. N. Bhattacharya, and R. A. Shanks, "Oxygen barrier property of polypropylene-polyether treated clay nanocomposite," Express Polymer Letters, vol. 2, no. 6, pp. 429-439, 2008.

[27] Z. Dehghan-Shoar, Z. Hamidi-Esfahani, and S. Abbasi, "Effect of temperature and modified atmosphere on quality preservation of Sayer date fruits (Phoenix Dactylifera L.)," Journal of Food Processing and Preservation, vol. 34, no. 2, pp. 323-334, 2010.

[28] X. Zhang and X. Shao, "Characterisation of polyphenol oxidase and peroxidase and the role in browning of loquat fruit," Czech Journal of Food Science, vol. 33, no. 2, pp. 109-117, 2016.

[29] Q. Shen, F. Kong, and Q. Wang, "Effect of modified atmosphere packaging on the browning and lignification of bamboo shoots," Journal of Food Engineering, vol. 77, no. 2, pp. 348354, 2006.

[30] A. I. Andrés, M. L. Timón, G. Molina, N. González, and M. J. Petrón, "Effect of MAP storage on chemical, physical and sensory characteristics of "niscalos" (Lactarius deliciosus)," Food Packaging and Shelf Life, vol. 1, no. 2, pp. 179-189, 2014.

[31] A. A. Khan and S. S. Malhotra, "Peroxidase activity as an indicator of $\mathrm{SO}_{2}$ injury in jack pine and white birch," Biochemie und Physiologie der Pflanzen, vol. 177, no. 8, pp. 643-650, 1982.

[32] H. S. Ramaswamy and S. Ranganna, "Residual peroxidase activity as influenced by blanching, $\mathrm{SO}_{2}$ treatment and freezing of cauliflowers," Journal of the Science of Food and Agriculture, vol. 47, no. 3, pp. 377-382, 1989.

[33] A. Chauhan, "Peroxidase isoenzyme profiles as indicators of sensitivity in $\mathrm{SO}_{2}$-fumigated crop plants," International Journal of Scientific Research in Science and Technology, vol. 2, no. 2, pp. 299-303, 2016.

[34] D. D. Davis, W. A. Payne, and L. J. Stief, “The hydroperoxyl radical in atmospheric chemical dynamics: reaction with carbon monoxide," Science, vol. 179, no. 4070, pp. 280-282, 1973.

[35] Y. Ma, X. Lu, J. F. Nock, and C. B. Watkins, "Peroxidase and polyphenoloxidase activities in relation to flesh browning of stem-end and calyx-end tissues of 'Empire' apples during controlled atmosphere storage," Postharvest Biology and Technology, vol. 108, pp. 1-7, 2015.

[36] A. Ait-Oubahou and E. Yahia, "Postharvest handling of dates," Postharvest News and Information, vol. 10, no. 6, pp. 67-74, 1999.

[37] S. M. Aleid, A. M. Elansari, T. Zhen-Xing, and A. A. Sallam, "Effect of cold storage and packing type on Khalas and Sukkary dates quality," Advance Journal of Food Science and Technology, vol. 6, no. 5, pp. 603-608, 2014.

[38] C. Barril, A. C. Clark, and G. R. Scollary, "Chemistry of ascorbic acid and sulfur dioxide as an antioxidant system relevant to white wine," Analytica Chimica Acta, vol. 732, pp. 186-193, 2012.

[39] L. Inserra, T. Cabaroglu, K. Şen, E. Arena, G. Ballistreri, and B. Fallico, "Effect of sulphuring on physicochemical characteristics andaroma of dried Alkaya apricot: a new Turkish variety," Turkish Journal of Agriculture and Forestry, vol. 41, no. 1, pp. 59-68, 2017.

[40] O. J. Ferrer, W. S. Otwell, and M. R. Marshall, "Effect of bisulfite on lobster shell phenoloxidase," Journal of Food Science, vol. 54, no. 2, pp. 478-480, 1989.

[41] N. P. Nirmal and S. Benjakul, "Use of tea extracts for inhibition of polyphenoloxidase and retardation of quality loss of Pacific white shrimp during iced storage," LWT - Food Science and Technology, vol. 44, no. 4, pp. 924-932, 2011. 